\title{
Article \\ Bray-Call Sequences in the Mediterranean Common Bottlenose Dolphin (Tursiops truncatus) Acoustic Repertoire
}

\author{
Daniela Silvia Pace ${ }^{1, *(1)}$, Carla Tumino ${ }^{1}\left(\mathbb{D}\right.$, Margherita Silvestri $^{2}$, Giancarlo Giacomini ${ }^{1}$, Giulia Pedrazzi ${ }^{1}$, \\ Gianni Pavan ${ }^{3}{ }^{\circ}$, Elena Papale ${ }^{4,5}{ }^{(}$, Maria Ceraulo ${ }^{4}$, Giuseppa Buscaino ${ }^{4}\left(\mathbb{D}\right.$ and Giandomenico Ardizzone ${ }^{1}$
}

1 Department of Environmental Biology, Sapienza University of Rome, 00185 Rome, Italy; tumino.1701635@studenti.uniroma1.it (C.T.); giancgiacomini@gmail.com (G.G.); g.pedrazzi06@gmail.com (G.P.); giandomenico.ardizzone@uniroma1.it (G.A.)

2 Department of Environmental and Evolutionary Sciences, University Austral of Chile, Valdivia 5090000, Chile; margherita.silvestri@alumnos.uach.cl

3 Department of Earth and Environmental Sciences, University of Pavia, 27100 Pavia, Italy; gianni.pavan@unipv.it

4 Consiglio Nazionale delle Ricerche-Istituto per lo Studio degli Impatti Antropici e Sostenibilità, Campobello di Mazara, 91021 Trapani, Italy; elena.papale@ias.cnr.it (E.P.); maria.ceraulo@ias.cnr.it (M.C.); giuseppa.buscaino@cnr.it (G.B.)

5 Department of Life Sciences and Systems Biology, University of Torino, 10123 Torino, Italy

* Correspondence: danielasilvia.pace@uniroma1.it; Tel.: +39-(0)6-4991-4763

\section{check for}

updates

Citation: Pace, D.S.; Tumino, C.;

Silvestri, M.; Giacomini, G.; Pedrazzi,

G.; Pavan, G.; Papale, E.; Ceraulo, M.;

Buscaino, G.; Ardizzone, G. Bray-Call

Sequences in the Mediterranean

Common Bottlenose Dolphin

(Tursiops truncatus) Acoustic

Repertoire. Biology 2022, 11, 367.

https://doi.org/10.3390/

biology11030367

\section{Academic Editor: Anna Di Cosmo}

Received: 24 January 2022

Accepted: 23 February 2022

Published: 25 February 2022

Publisher's Note: MDPI stays neutral with regard to jurisdictional claims in published maps and institutional affiliations.

Copyright: (C) 2022 by the authors. Licensee MDPI, Basel, Switzerland. This article is an open access article distributed under the terms and conditions of the Creative Commons Attribution (CC BY) license (https:// creativecommons.org/licenses/by/ $4.0 /)$.
Simple Summary: In the acoustic repertoire of common bottlenose dolphins (Tursiops truncatus), Gulps, Grunts, and Squeaks are part of a group of vocalizations called "bray-call" for which little has been previously studied. The name comes from the alternating structure characteristic of a donkey's bray. Sounds can be of different types at low frequencies and audible to the human hear-of short duration, produced in sequence. The function of these sequences is not clarified yet, and it is not known if they are part of the vocal "catalog" of all the different populations of common bottlenose dolphin at global level. What is certain is that bray-calls are present in two geographical areas of the Mediterranean and that the "Capitoline" individuals (Rome, Tyrrhenian Sea, Italy) emit them with greater frequency and variety than the Sicilian ones (Mazara del Vallo, Sicilian Channel, Italy). A number of 13 different types of sequences have been identified, and only 2 of them are shared between the study areas. For the first time this study identifies variants of the main bray-call elements, highlights the structural complexity of these vocalizations, and suggests addressing future research on the context of emissions and the possible function(s) of such acoustic arrangements.

Abstract: Acoustic sequences are commonly observed in many animal taxa. The vast vocal repertoire of common bottlenose dolphins (Tursiops truncatus) also includes sequences of multi-unit rhythmic signals called bray-call which are still poorly documented, both functionally and geographically. This study aimed to (1) describe, classify, and characterize series of bray-call recorded in two sites of the Mediterranean basin (Rome-Tyrrhenian Sea and Mazara del Vallo-Strait of Sicily) and (2) investigate for the existence of possible geographic differences. The acoustic analysis identified 13 different sequence types, only two detected in both study areas. The Sørensen-Dice index revealed a low degree of similarity between the sequence repertoire of the two common bottlenose dolphin sub-populations, with the Tyrrhenian being more diversified and complex than the Sicilian one. The acoustic parameters also showed variability between the study area. Different variants of the main acoustic elements composing the bray-call sequences were detected in the Tyrrhenian Sea only. The Markov-chain model demonstrated that the transition probability between acoustic elements is not uniform, with specific combinations of elements having a higher probability of occurrence. These new findings on common bottlenose dolphin bray-call sequences highlight the structural complexity of these vocalizations and suggest addressing future research on the context of emissions and the possible function(s) of such acoustic arrangements. 
Keywords: acoustic sequences; bray-call; geographical differences; common bottlenose dolphin; Tursiops truncatus; Mediterranean Sea

\section{Introduction}

Sequences of distinct acoustic elements are a widely spread feature of animal acoustic repertoire. They are used mainly in communication and often contain valuable information beneficial for the receiver [1]. Acoustic sequences can convey evidence of individual identity in many species (e.g., frog and insects [2]; common starling, Sturnus vulgaris [3]; grey wolf, Canis lupus lycaon [4]; common bottlenose dolphin, Tursiops truncatus [5]; long-finned pilot whale, Globicephala melas [6]), as well as context-related information, such as resources availability (e.g., chimpanzees, Pan troglodytes [7]) or predation risk (e.g., Marmota spp. [8]; primates, Colobus polykomos and Colobus guereza [9]). However, there are many cases in which the ultimate function of the acoustic sequences is still poorly understood.

Since acoustic sequences are composed of distinct elements (i.e., acoustic units [1]), identifying and distinguishing their relevant components is a preliminary step to understand their structure, potential meaning, and possible function. Characterizing a sequence, and its emission context, is crucial to determining which kind of information it may contain and how this information may be encoded in its structure [1]. According to the classification method proposed by [1], information can be codified within the acoustic sequences following six different paradigms: (a) Repetition, where a single unit is repeated more than once; (b) Diversity, where information is represented by the number of distinct units present; (c) Combination, where sets of units have different information from each unit individually; (d) Ordering, where the relative position of units to each other is important; (e) Overlapping, where information is conveyed in the relationship between sequences of two or more individuals; and (f) Timing, where the time gap between units conveys information.

The production of multi-element acoustic sequences is documented in several cetacean species (e.g., sperm whale, Physeter macrocephalus: [10,11]; killer whale, Orcinus orca [12]; humpback whale, Megaptera novaeangliae [13]; long-finned pilot whale, Globicephala melas [14]). The complex vocal repertoire of common bottlenose dolphin also includes repeated acoustic sequences such as the signature whistle identity calls $[15,16]$. Among them, this species emits sequences of multi-unit rhythmic signals known as bray-call series $[17,18]$. These sequences have been recorded for the first time during social interactions in the Sado estuary, Portugal $[19,20]$ and have been detected occasionally in other populations (e.g., [21-23]), also in feeding contexts [24,25]. dos Santos et al. [19] described the bray-call series as sequences of two alternating sounds: a "squeak" (a pulsed sound with a repetition rate of 10-20 click/s, duration ranging 1-2 s and peak frequency ranging 4-6 kHz) and a "grunt" (a low-frequency continuous not pulsed sound), subsequently renamed "gulp" five years later [20]. A similar structure for bray-call sequences was suggested by [24], that described them being composed of a burst-pulsed sound and a short downsweep low-frequency sound. Lately, Janik et al. [17] described the bray-call sequences as composed by a variable number and type of units with three main acoustic elements: "gulp" (impulsive lowfrequency sound), "grunt" (series of broadband impulsive signals with most of the energy at low frequencies), and "squeak" (pulsed sound perceived as a tonal sound by the human ear). Three typical and well-defined call arrangements were identified: single-unit gulp or grunt sequences, and multi-unit sequences that contain squeaks [17]. This variability in the composition of the sequences was ascribed to possible different meanings of the units, suggesting the existence of diversity, combination, repetition, time, and order rules $[1,17]$.

Bray-calls are still poorly documented, functionally and geographically [17]. This study aims to provide a detailed structural description, classification, and characterization of the bray-call sequences recorded in two different areas of the Mediterranean Sea (RomeTyrrhenian Sea and Mazara del Vallo-Strait of Sicily). In addition, the possible presence 
of geographical differences between sub-populations within the basin was investigated comparing acoustic data from the two sites.

\section{Materials and Methods}

\subsection{Study Area}

Recordings were collected in the central Mediterranean (Rome, Tyrrhenian Sea) and the Strait of Sicily (Mazara del Vallo) (Figure 1).

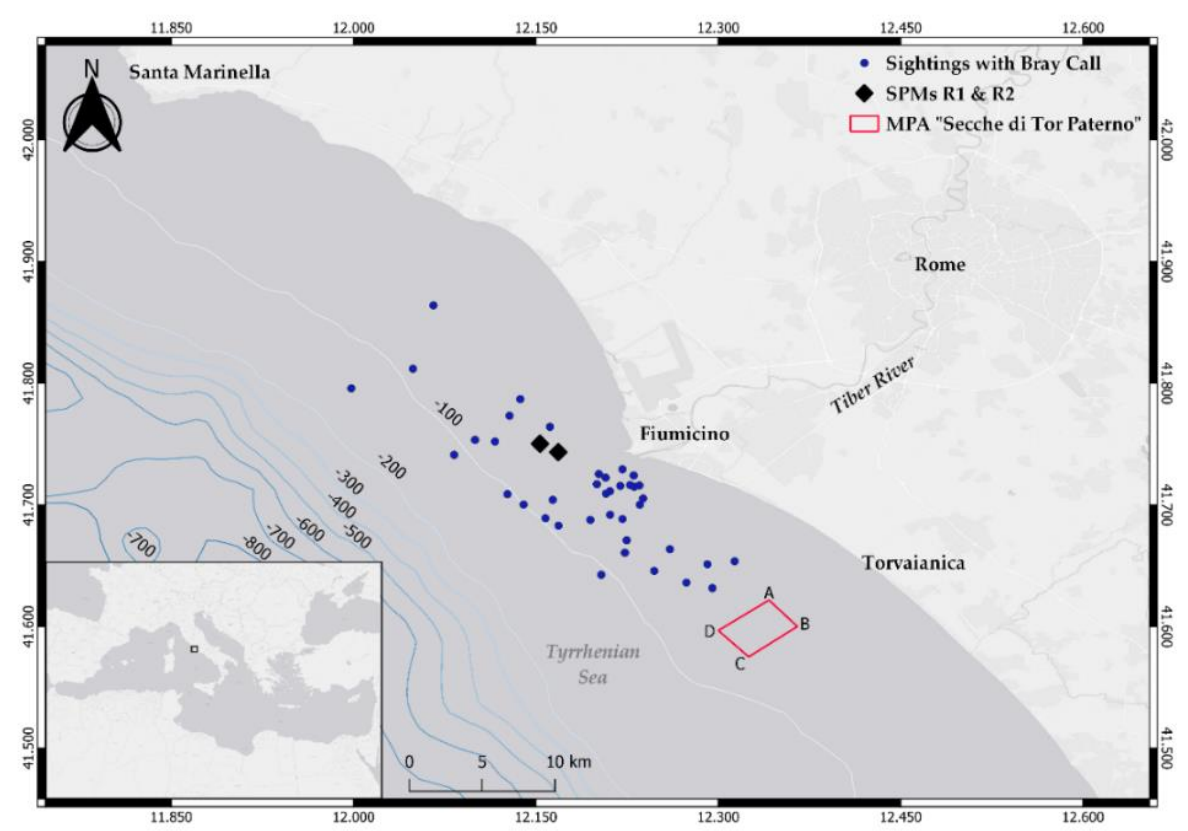

(a)

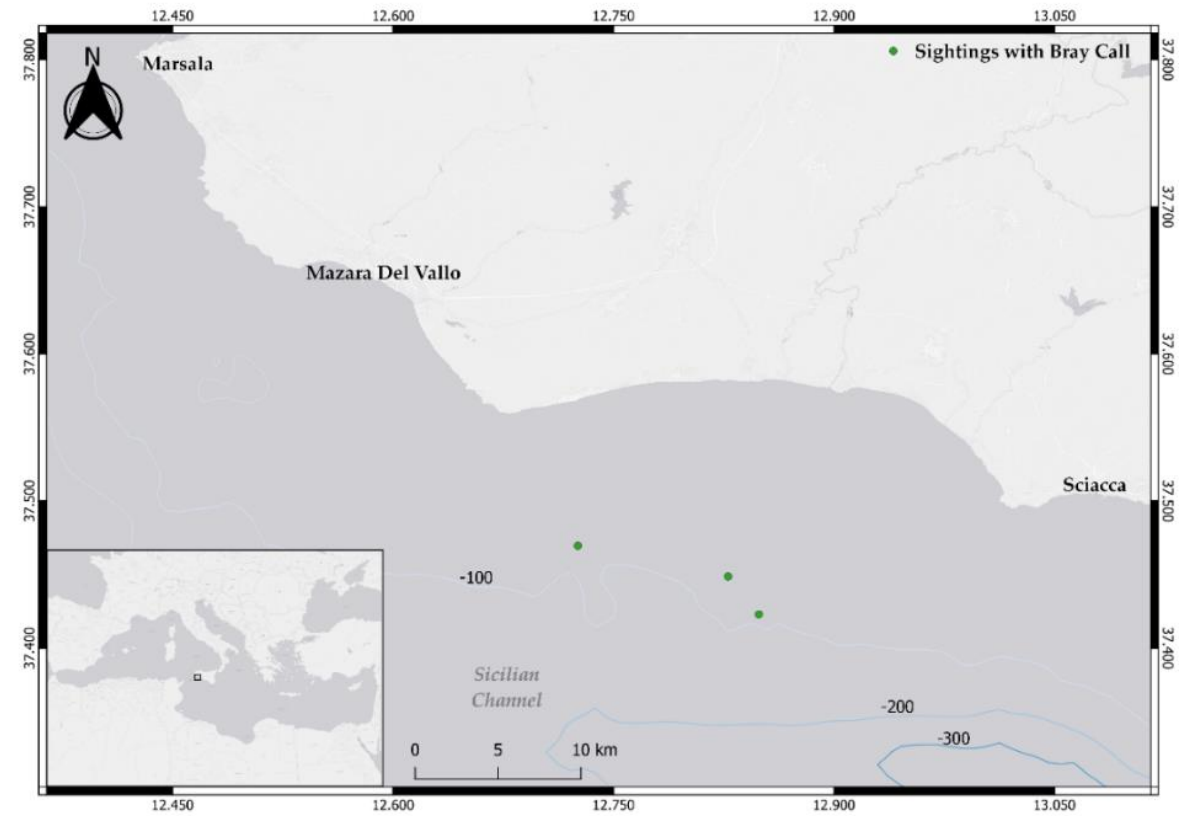

(b)

Figure 1. Maps of the two study sites. (a) Tyrrhenian Sea. The two black rhombi represent the single point moorings R1 and R2; the red rectangle identifies the "Secche di Tor Paterno" MPA; blue dots show the spatial distribution of the common bottlenose dolphin encounters with bray-call detections. (b) Strait of Sicily. The green dots show the spatial distribution of the common bottlenose dolphin encounters with bray-call detections. 
The Tyrrhenian Sea site covers an area of approximately $1300 \mathrm{~km}^{2}$ and includes the estuary of the Tiber River (bottom depth up to $100 \mathrm{~m}$ ). A variety of habitats and environmental conditions characterize the site, with a rich coastal biodiversity principally maintained by the organic matter transported at sea through the river (for a detailed description of the site see [26]). This area is exposed to intense anthropic activity, with a strong level of vessel traffic generated by both tourism and commercial fishery (artisanal and trawling vessels [26,27]), and the effect [28] of two fixed single-point moorings (SPMs, called R1 and R2) receiving crude oil located three nautical miles away from the river estuary. The regular occurrence of groups of common bottlenose dolphin is here reported [29], with numerous sightings of mother and calf pairs, feeding activities, and significant interactions with fishing gears (both trawls and gillnets), allowing the area being identified as a foraging and nursery ground for the species [26,27].

The Strait of Sicily site divides the Tyrrhenian and the western Mediterranean Sea from the eastern side of the basin. More specifically, the study area covers approximately $1440 \mathrm{~km}^{2}$ and is located in the north-western side of the strait, along the southern coast of Sicily, between Mazara del Vallo and Sciacca. This area is characterized by a wide and not very deep continental shelf (Adventure Plateau), with a maximum depth of $200 \mathrm{~m}$, and is exposed to intense vessel traffic, being one of the main routes for commercial shipping and fishery. The regular presence of common bottlenose dolphins has been documented in the area, with frequent interactions between common bottlenose dolphins and fishery [30,31].

\subsection{Data Collection}

Acoustic recordings were collected during boat-based daily surveys in both study sites (Table 1) in different years with different methods and equipment. In the Tyrrhenian Sea the sampling effort was conducted for 4-5 months per year (June-October), while in the Strait of Sicily the sampling effort was conducted for 3 months per year (JulySeptember). When a group of dolphins (i.e., two or more individuals involved in similar behavior within a range of $100 \mathrm{~m}$ one from the other; [32]) was sighted, GPS position, time, group size, and composition (based on the classification reported in [26]), predominant behavior (i.e., the behavioral state in which more than half of the individuals within the group are involved; [33]), acoustic emissions, and interaction with fishing gears (if any) were recorded. Photographs of dorsal fins were collected using digital cameras equipped with zoom lens, and then used for identification purposes (details on photo-identification procedures in $[26,34])$.

Table 1. Survey platforms and methods for data collection, acoustic equipment, total recording effort and sampling periods for the two research sites.

\begin{tabular}{|c|c|c|c|c|}
\hline Site & Platform and Survey Methods & Acoustic Equipment & $\begin{array}{l}\text { Recording } \\
\text { Effort }\end{array}$ & Year \\
\hline $\begin{array}{l}\text { Strait of } \\
\text { Sicily }\end{array}$ & $\begin{array}{l}\text { Boat-based survey using a motorboat } \\
\text { powered by a four-stroke } 100 \mathrm{HP} \\
\text { outboard engine, in suitable weather } \\
\text { conditions (sea state }<4 \text { Douglas, wind } \\
\text { force Beaufort }<4 \text {, no rain, no fog), at a } \\
\text { steady speed of } 6-8 \mathrm{kn} \text {. } \\
\text { Both non-systematic haphazard } \\
\text { (sensu [35]) and systematic } \\
\text { sampling procedure. } \\
\text { More details in [30,31]. }\end{array}$ & $\begin{array}{c}\text { One omnidirectional hydrophone } \\
\text { Bruel e Kjer (Nærum, Denmark) } \\
\text { model } 8104 \text { (sensitivity }-205.6 \mathrm{~dB} \text { re } \\
1 \mathrm{~V} / 1 \mu \mathrm{Pa} \pm 4.0 \mathrm{~dB} \text { ), with a } \\
\text { bandwidth }<0.1 \mathrm{~Hz} \text { to }>80 \mathrm{kHz} \text { ) } \\
\text { One digital sound card Avisoft } \\
\text { Bioacoustics USGH } 416 \mathrm{HB} \text { (data } \\
\text { format 16-24-bit WAV, sampling rate } \\
44.1,48 \text { and } 96 \mathrm{ks} / \mathrm{s}[36]) .\end{array}$ & $\begin{array}{c}3.8 \mathrm{~h}, \\
\text { resulting in } \\
422 \text {.wav files }\end{array}$ & 2012-2015 \\
\hline
\end{tabular}


Table 1. Cont.

\begin{tabular}{|c|c|c|c|c|}
\hline Site & Platform and Survey Methods & Acoustic Equipment & $\begin{array}{l}\text { Recording } \\
\text { Effort }\end{array}$ & Year \\
\hline $\begin{array}{l}\text { Tyrrhenian } \\
\text { Sea }\end{array}$ & $\begin{array}{c}\text { Boat-based survey using a sailing vessel } \\
\text { Beneteau Oceanis } 41.1 \text { powered by a } \\
55 \mathrm{hp} \text { Volvo diesel engine, in suitable } \\
\text { weather conditions } \\
\text { (sea state }<3 \text { Douglas, wind force } \\
\text { Beaufort }<3 \text {, no rain, no fog), at a } \\
\text { steady speed of } 4-6 \mathrm{kn} . \\
\text { Non-systematic haphazard sampling } \\
\text { procedure (sensu [35]). } \\
\text { More details in [26]. }\end{array}$ & $\begin{array}{c}\text { 2017-2018: Two Colmar } \\
\text { omnidirectional hydrophones (La } \\
\text { Spezia, Italia) model GP0280 } \\
\text { provided by CIBRA-Pavia } \\
\text { University (sensitivity -168.8 dB re } \\
1 \mathrm{~V} / \mu \mathrm{Pa} @ 5 \mathrm{kHz} \text {, flat frequency } \\
\text { response from } 1 \text { to } 30 \mathrm{kHz} \pm 5 \mathrm{~dB} \text { ), } \\
\text { with a bandwidth } 5 \mathrm{~Hz}-90 \mathrm{kHz} \\
\text { 2019-2020: One towed hydrophone } \\
\text { Aquarian Audio (Anacortes, WA, } \\
\text { USA) model H1c-2018 provided by } \\
\text { Nauta srl (sensitivity -199 dB re } \\
1 \mathrm{~V} / \mu \text { Pa, flat frequency response } \\
\text { from } 20 \mathrm{~Hz} \text { to } 4 \mathrm{kHz} \pm 4 \mathrm{~dB} \text { ), with a } \\
\text { bandwidth }<0.1 \text { to }>100 \mathrm{kHz} \text {. } \\
\text { Digital sound card Roland Quad } \\
\text { Capture UA55 (data format } \\
\text { 16-24-bit WAV, sampling rate } 44.1 \text {, } \\
48 \text { and } 96 \mathrm{ks} / \mathrm{s} \text { [36]). }\end{array}$ & $\begin{array}{l}115.3 \mathrm{~h} \text {, } \\
\text { resulting in } \\
871 \text {.wav files }\end{array}$ & $2017-2020$ \\
\hline
\end{tabular}

\subsection{Acoustic Analysis}

Recordings from the two study sites were first examined to select those containing bray-call series. Visual inspection of the spectrogram was conducted using the software Raven Pro 1.6 [37] with the following settings: Hann window 2048, DFT 2048, Overlap $50 \%$, Hop size 1024. Analysis parameters were optimized to improve signal visualization. The acoustic analysis was conducted on sequences composed by the succession and the combination of acoustic units classified as bray-call elements by [17]: gulp, GU; grunt, GR; and squeak, SQ. The element types were considered as part of the same sequence if the inter-element interval was shorter than 1 min [24]. Other sounds than GU, GR, and SQ were recorded within sequences. These sounds included Pops (POP; low frequency pulsed sound with most energy between 0.3 and $3.0 \mathrm{kHz}$ [38]), Cracks (CR; broadband intense, single clicks with most of energy between 0.1 and $8.0 \mathrm{kHz}$ [18]), and Low-Frequency Narrowband sounds (LFN; short downsweep sounds with fundamental frequency lower than $2 \mathrm{kHz}$ [18]). They were considered part of the bray-call series if detected within the sequence and less than one minute apart from a bray-call element.

Each sequence and each element type composing the sequence were characterized by measuring the parameters described in Table 2 and presented in Figure 2. All the variables were extracted using Raven Pro 1.6 and only high-quality sequences (i.e., sequences in which all parameters were measurable) were considered in this work.

Main bray-call elements (GU, GR, and SQ) were generally described without intratype variability. Here, four variants (or "subtypes") of GU and two variants of GR were identified (Figure 3). A variant was defined as an acoustic unit that can be ascribed to a specific bray-call element type (as described in the literature for its aural and visual characteristics) but showing peculiar acoustic features that allow it to be distinguished from other variants of the same element type. The variants were categorized assigning an identification code composed of the abbreviation of the corresponding element type followed by a number (e.g., the first GU variant was coded as GU1). In this way, it was possible to classify each sequence by the pattern of succession and/or combination of the types/variants of the acoustic elements, and apply the paradigms proposed by [1] for encoding information. 
Table 2. Definition of acoustic parameters measured for each bray call series and for each single element composing the sequence.

\begin{tabular}{cc}
\hline Parameter & Description \\
\hline Element type & Type of acoustic element composing the sequence \\
Acoustic elements in the sequence $(\mathrm{N})$ & Number of detectable elements composing each sequence \\
Sequence duration (s) & Time interval between the beginning of the first and the end of the last element \\
Element duration $(\mathrm{s})$ & Duration of each element in the sequence \\
Inter-element interval $(\mathrm{s})$ & Time interval between the end of an element and the beginning of the following one \\
Minimum Frequency $(\mathrm{Hz})$ & The lower frequency of each element composing the sequence \\
Maximum Frequency (Hz) & The higher frequency of each element composing the sequence \\
Peak frequency $(\mathrm{Hz})$ & The frequency with maximum amplitude in the spectrum (for POP and CR element types) \\
\hline
\end{tabular}

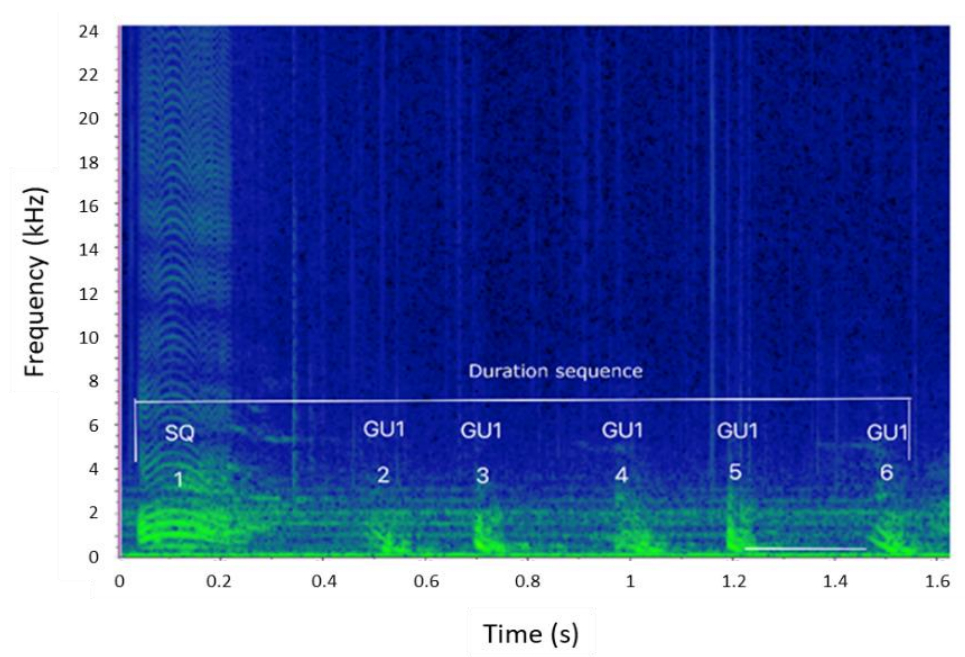

(a)

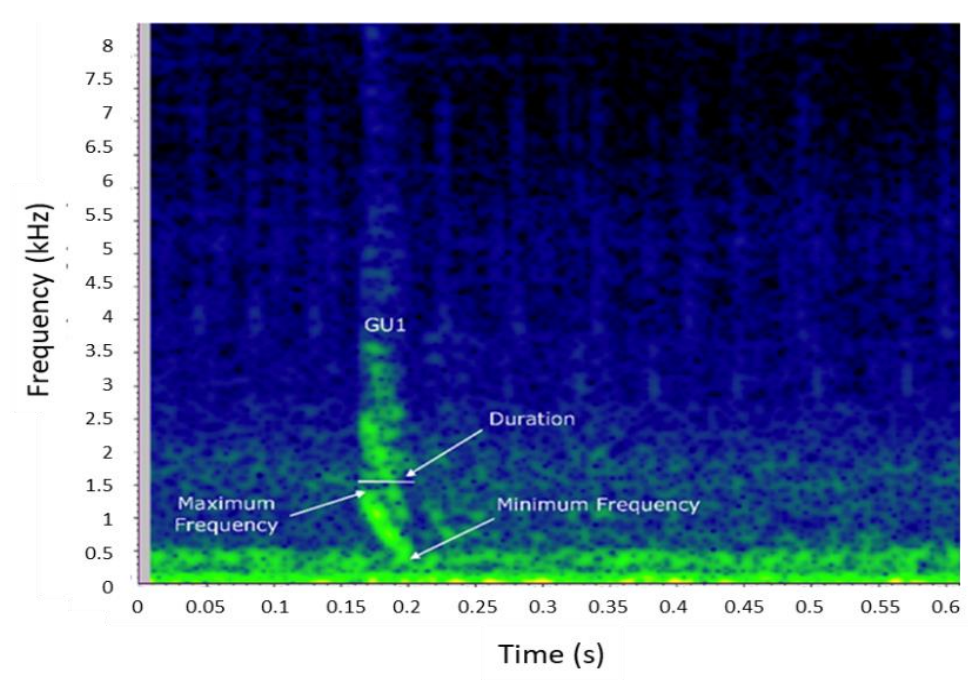

(b)

Figure 2. (a) Spectrogram of a bray-call series indicating the parameters measured for the sequence (duration, type, and number of elements composing the sequence) and inter-element interval (period) (Hann window, size 2048, DFT 2048, overlap 50\%, hop size 1024, sampling frequency $192 \mathrm{kHz}$, frequency resolution $93.75 \mathrm{~Hz}$, analysis bandwidth $135 \mathrm{~Hz}$ at $-3 \mathrm{~dB}$ ). (b) Spectrogram of a single Gulp (GU) showing the acoustic parameters extracted for the element (Hann window, size 3000, DFT 4096, overlap 80\%, hop size 600, sampling frequency $192 \mathrm{kHz}$, frequency resolution $46.875 \mathrm{~Hz}$, analysis bandwidth $92.16 \mathrm{~Hz}$ at $-3 \mathrm{~dB}$ ). 

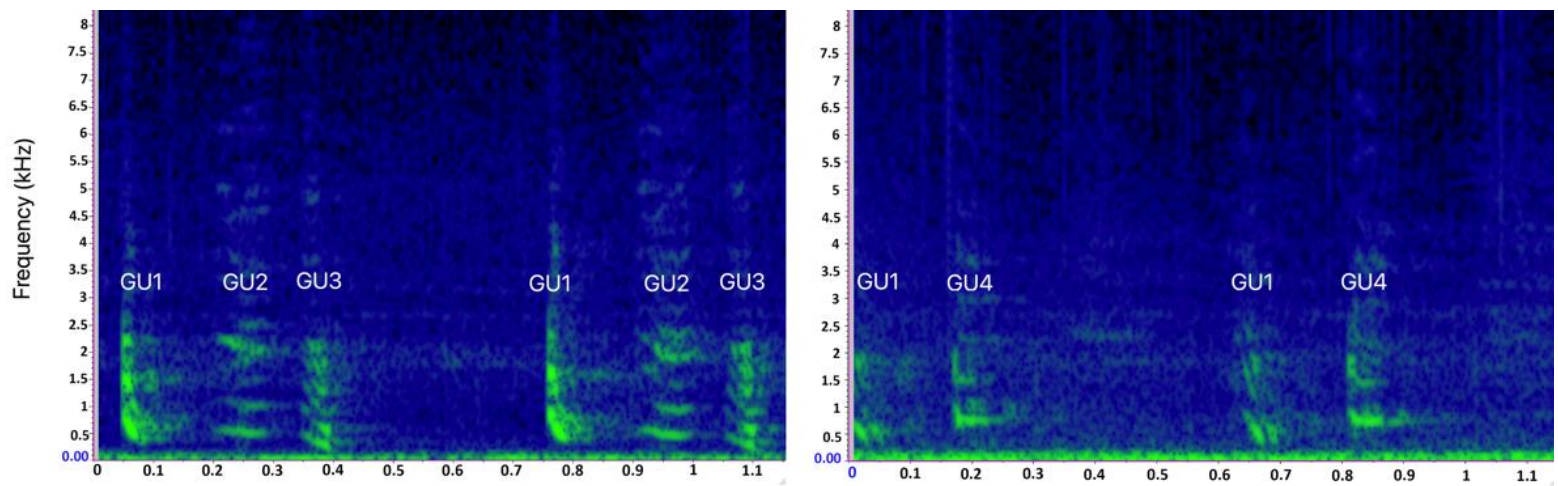

(a)
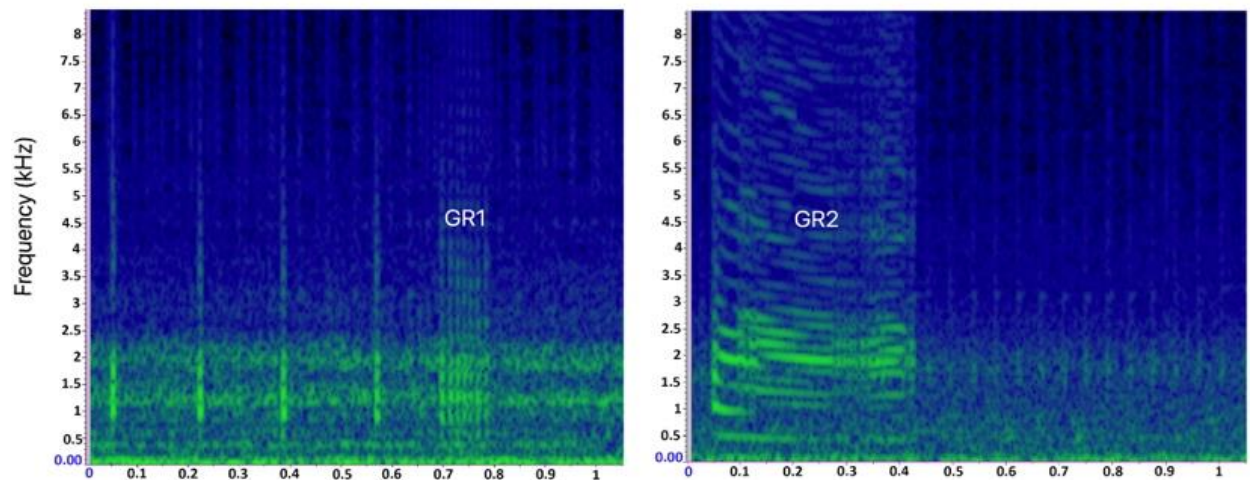

Time (s)

(b)

Figure 3. (a) Spectrograms of the 4 different Gulp variants (GU1, GU2, GU3, and GU4) identified in this study. (b) Spectrograms of the two different Grunt variants (GR1 and GR2) identified in this study (Hann window, size 3000, DFT 4096, overlap 80\%, hop size 600, sampling frequency $192 \mathrm{kHz}$, frequency resolution $46.875 \mathrm{~Hz}$, analysis bandwidth $92.16 \mathrm{~Hz}$ at $-3 \mathrm{~dB}$ ).

\subsection{Descriptive and Statistical Analysis}

The structural and temporal characteristics of the bray-call series were assessed using a first-order Markov chain model (FOMM) [39]. To evaluate the structural complexity within these bray-call series, Shannon entropic orders [40] were calculated as:

$$
H_{1}=\sum_{i=1}^{N} p i \log _{2} p i
$$

where $N$ is the number of different acoustic elements and $p i$ is the probability of the $i$-th acoustic element in a bray-calls series. The FOMM was first applied to the acoustic elements identified as bray-call in the literature (GU, GR, and SQ) [17] and then repeated considering the different variants identified for the first time in this study.

The acoustic parameters extracted from the sequences found in both study areas were compared to investigate for any geographical difference. All continuous quantitative variables were tested for normality distribution through the Shapiro-Wilk test. In case of normal distribution, Welch's $t$-test were applied, while non-normally distributed variables were tested through the Mann-Whitney and Kruskal-Wallis tests. An index derived from the Sørensen-Dice coefficient of association (SDC) was applied to obtain a measure of the similarity between the bray-call sequence repertoires of the two common bottlenose dolphin sub-populations. The index was computed from the degree of sequence typologies 
and acoustic element types shared and accounts for differences in the repertoire size. The Sørensen-Dice index was calculated as

$$
\mathrm{SDC}=2(\mathrm{Ns}+\mathrm{Ne}) /(\mathrm{R} 1+\mathrm{R} 2)
$$

where Ns is the total number of sequences shared, Ne is the total number of acoustic elements shared, and R1 and R2 are the repertoire sizes of the two sub-populations (distinct sequences + acoustic elements). All analysis were performed in R 4.0.3 (www.r-project.org; accessed 18 December 2021).

\section{Results}

Overall, 1293 .wav files, corresponding to $119 \mathrm{~h}$ of recordings, were examined, $134 \mathrm{of}$ which containing bray-call series. A total of 644 high-quality bray-call sequences including 4030 acoustic elements were analyzed, with 637 in the Tyrrhenian Sea (0.09 sequence/min) and 7 in the Strait of Sicily (0.03 sequence/min). A total of 13 different typologies of stereotyped sequences were identified (Table 3, Figures 4 and 5), all of them detected in the Tyrrhenian Sea and only two in the Strait of Sicily. These bray-call series met five distinct paradigms suggested by [1] for information encoding (repetition, diversity, combination, ordering, and timing; Figure 6). Although more than one animal was spotted during recordings, overlapping between different sequences was never observed.

Table 3. Parameters measured for each bray call series and for each single element composing the sequence.

\begin{tabular}{|c|c|c|c|}
\hline Element Type & $\begin{array}{l}\text { Sequence Id } \\
\text { Number }\end{array}$ & $\begin{array}{l}\text { ID Element Type/Subtype } \\
\text { (N of Elements) }\end{array}$ & Description \\
\hline \multirow{4}{*}{ Gulp (GU) } & 1 & GU1 (1711) & $\begin{array}{l}\text { A single-element sequence composed of Gulp } \\
\text { (GU1) repeated in series of } 3 \text { to } 105 \text { elements }\end{array}$ \\
\hline & 2 & GU3 (233)-GU1 (229) & $\begin{array}{l}\text { A multi-element sequence composed of } 4 \text { to } \\
32 \text { elements containing the repetition of Gulp } \\
\text { pairs (GU3 and GU1) }\end{array}$ \\
\hline & 3 & GU1 (97)-GU4 (93) & $\begin{array}{c}\text { A multi-element sequence containing the } \\
\text { repetition of Gulp pairs (GU1 and GU4), with } \\
8 \text { to } 11 \text { GU1 and } 3 \text { to } 23 \text { GU4 elements } \\
\text { per sequence }\end{array}$ \\
\hline & 4 & GU1 (108)-GU2 (97)-GU3 (107) & $\begin{array}{l}\text { A multi-element sequence containing the } \\
\text { repetition of Gulp triplets (GU1, GU2 and GU3), } \\
\text { with the repetition of } 2 \text { to } 22 \text { GU1, } 2 \text { to } 20 \text { GU2 } \\
\text { and } 2 \text { to } 22 \text { GU3 elements per sequence }\end{array}$ \\
\hline $\begin{array}{l}\text { Gulp (GU) and } \\
\text { Pop (POP) }\end{array}$ & 5 & GU1 (32)-POP (412) & $\begin{array}{c}\text { A multi-element sequence containing a series of } \\
\text { POPs, alternated with } 1 \text { to } 8 \text { Gulp (GU1). The } \\
\text { number of POP ranged from } 9 \text { to } 27 \text {, while the } \\
\text { number of POP series within the sequence } \\
\text { varied from } 1 \text { to } 16\end{array}$ \\
\hline \multirow{3}{*}{$\begin{array}{l}\text { Grunt (GR) and } \\
\text { Gulp (GU) }\end{array}$} & 6 & GR1 (5)-GU1 (94) & \multirow{3}{*}{$\begin{array}{l}\text { A multi-element sequence containing a Grunt } \\
\text { (GR1) followed by a series of } 6 \text { to } 35 \text { Gulp (GU1) } \\
\text { A multi-element sequence containing a Grunt } \\
\text { (GR1) and a Gulp (GU1) alternated, with } \\
\text { 3-9 GR1 and } 3 \text { to } 11 \text { GU1 elements per sequence } \\
\text { A multi-element sequence containing a Grunt } \\
\text { (GR2) followed by a series of } 3 \text { to } 26 \text { Gulp (GU1) }\end{array}$} \\
\hline & 7 & GR1 (45)-GU1 (46) & \\
\hline & 8 & GR2 (20)-GU1 (142) & \\
\hline $\begin{array}{l}\text { Crack (CR), Grunt } \\
(\mathrm{GR}) \text { and Gulp (GU) }\end{array}$ & 9 & CR (157)-GR1 (34)-GU1 (34) & $\begin{array}{c}\text { A multi-element sequence containing a series } \\
\text { of } 2-11 \text { Cracks (CR) followed by a Grunt (GR1) } \\
\text { and a Gulp (GU1) }\end{array}$ \\
\hline
\end{tabular}


Table 3. Cont.

\begin{tabular}{cccc}
\hline Element Type & $\begin{array}{c}\text { Sequence Id } \\
\text { Number }\end{array}$ & $\begin{array}{c}\text { ID Element Type/Subtype } \\
\text { (N of Elements) }\end{array}$ & Description \\
\hline Squeak (SQ) & 10 & SQ (61) & $\begin{array}{c}\text { A single-element sequence composed of Squeaks } \\
\text { (SQ) repeated in series of 2 to 14 elements }\end{array}$ \\
\hline $\begin{array}{c}\text { Squeak (SQ) and } \\
\text { Gulp (GU) }\end{array}$ & 11 & SQ (47)-GU1 (41) & $\begin{array}{c}\text { A multi-element sequence containing a Squeak } \\
\text { (SQ) and a Gulp (GU1) alternated, with 2 to } \\
\text { 13 SQ and 2 to 8 GU1 elements per sequence } \\
\text { A multi-element sequence containing a Squeak } \\
\text { (SQ) followed by a series of 3 to 27 Gulps (GU1) }\end{array}$ \\
\hline $\begin{array}{c}\text { Low-Frequency } \\
\text { Narrowband sounds } \\
\text { (LNF) and } \\
\text { Gulp (GU) }\end{array}$ & 12 & SQ (14)-GU1 (119) & A multi-element sequence containing a LFN and \\
a Gulp (GU1) alternated, with 4-6 LFN and 3 to \\
17 GU1 elements per sequence
\end{tabular}
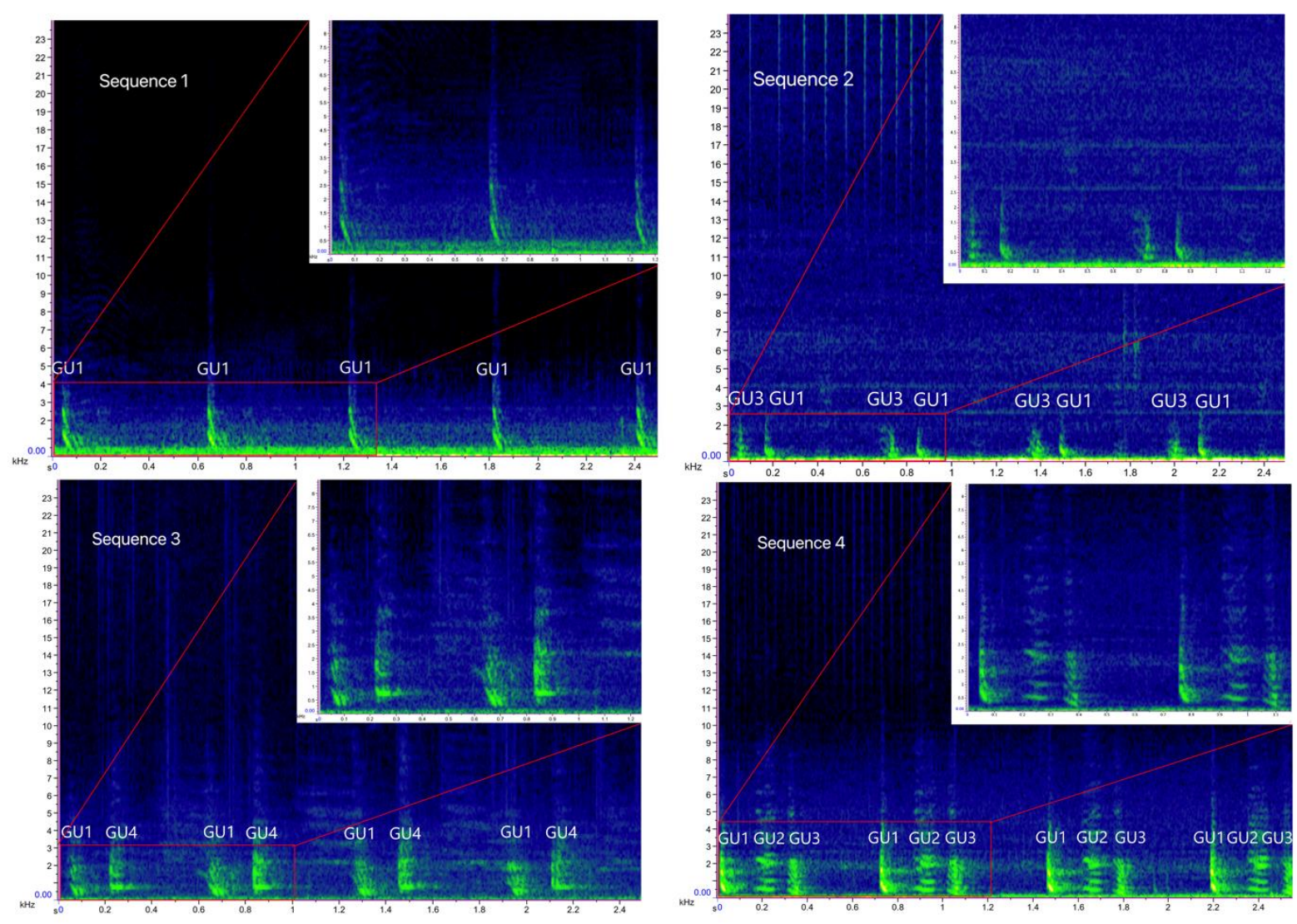

Figure 4. Cont. 

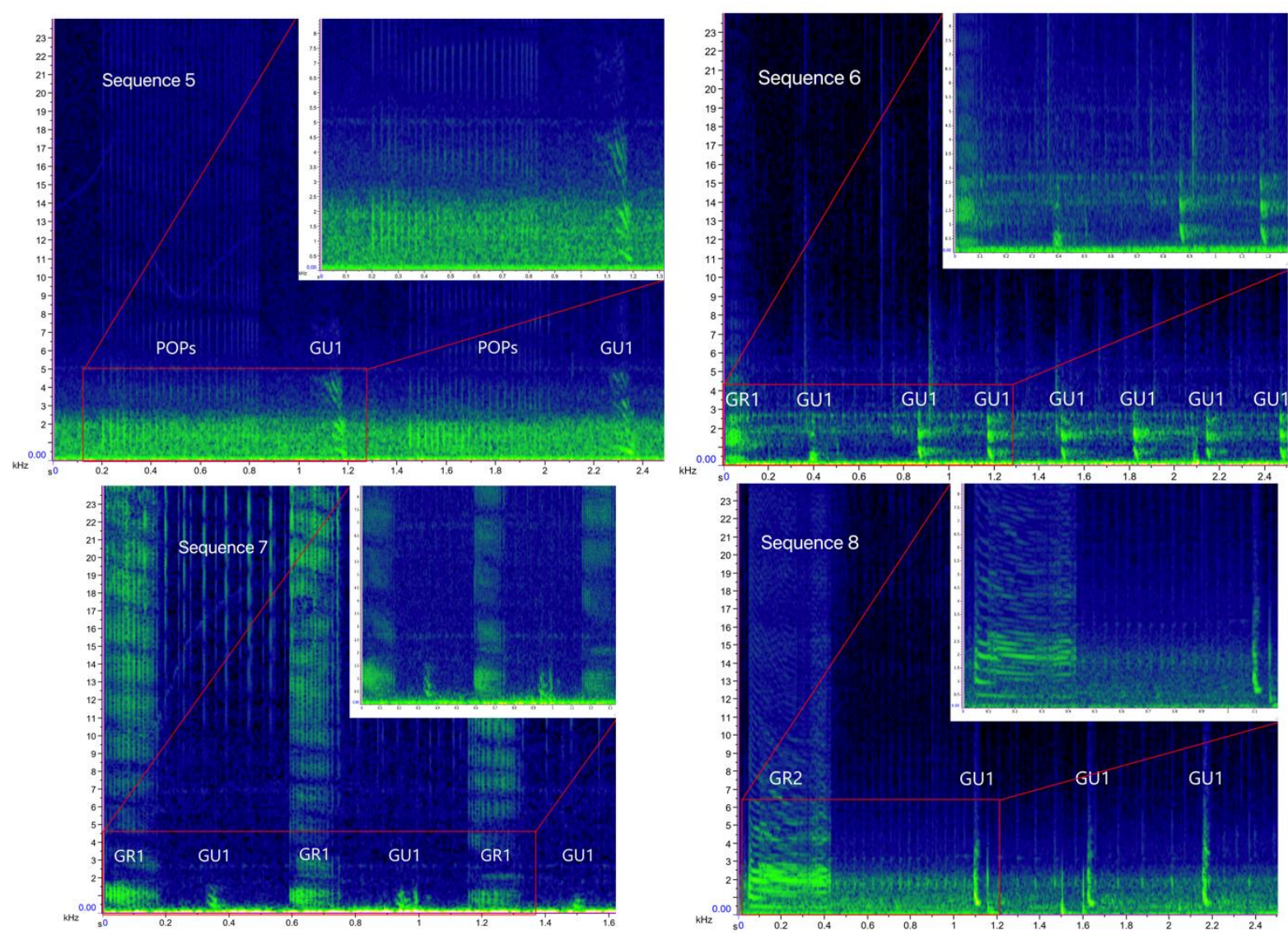

Figure 4. Spectrograms of the bray-call sequences 1-8 identified in the present study (main panels: Hann window, size 2048, DFT 2048, overlap 50\%, hop size 1024, sampling frequency $192 \mathrm{kHz}$, frequency resolution $93.75 \mathrm{~Hz}$, analysis bandwidth $135 \mathrm{~Hz}$ at $-3 \mathrm{~dB}$ ); zoomed panels: Hann window, size 3000, DFT 4096, overlap 80\%, hop size 600, sampling frequency $192 \mathrm{kHz}$, frequency resolution $46.875 \mathrm{~Hz}$, analysis bandwidth $92.16 \mathrm{~Hz}$ at $-3 \mathrm{~dB}$ ).

Sequence 1 accounted for $53.4 \%$ in the Tyrrhenian Sea $(n=340)$, followed by sequence $2(n=78)$, sequence $9(n=36)$, sequences 5 and $10(n=27$ and $n=26$ respectively), and sequences 7 and $8(n=25$ each); the other five sequences were about $2.5 \%$ each. In the Strait of Sicily, only single-element sequence $1(85.7 \%)$ and $10(14.3 \%)$ were detected. Indeed, the Sørensen-Dice index revealed a low degree of similarity between the sequence repertoire of the two common bottlenose dolphin populations (similarity, SDC $=0.27$ ), with the Tyrrhenian being more diversified and complex than the Sicilian one.

As shown in Table 3, the primary element type composing the sequences was Gulp $(80 \%)$. The variant GU1, present in all multi-element sequences, had down-sweep contour, no harmonic-like structure, and a wider frequency range than all other Gulp variants (minimum frequency $=295 \pm 94 \mathrm{~Hz}, \mathrm{CI}=291-299 \mathrm{~Hz}$; maximum frequency $=773 \pm 61 \mathrm{~Hz}$, $\mathrm{CI}=766-779 \mathrm{~Hz}$; duration $=0.04 \pm 0.01 \mathrm{~s}, \mathrm{CI}=0 \mathrm{~s})$. The variant $\mathrm{GU} 2$ had a mostly flat shape and a harmonic-like structure (minimum frequency $=361 \pm 83 \mathrm{~Hz}, \mathrm{CI}=345-378 \mathrm{~Hz}$; maximum frequency $=584 \pm 70 \mathrm{~Hz}, \mathrm{CI}=570-598 \mathrm{~Hz}$; duration $=0.04 \pm 0.01 \mathrm{~s}, \mathrm{CI}=0.04-0.07 \mathrm{~s}$ ). As GU1, the variant GU3 had a down-sweep contour, but presented a harmonic-like structure and lower minimum and maximum frequency (minimum frequency $=2168 \pm 45 \mathrm{~Hz}$, $\mathrm{CI}=210-221 \mathrm{~Hz}$; maximum frequency $=541 \pm 78 \mathrm{~Hz}, \mathrm{CI}=538-550 \mathrm{~Hz}$; duration $=0.04 \mathrm{~s}$, $\mathrm{CI}=0 \mathrm{~s})$. As GU2, the variant GU4 also had a mostly flat shape, but without a harmonic structure, and higher minimum and maximum frequency than all other Gulp variants (minimum frequency $=592 \pm 71 \mathrm{~Hz}, \mathrm{CI}=588-597 \mathrm{~Hz}$; maximum frequency $=868 \pm 86 \mathrm{~Hz}$, $\mathrm{CI}=851-886 \mathrm{~Hz}$; duration $=0.07 \pm 0.06 \mathrm{~s}, \mathrm{CI}=0.03-0.06 \mathrm{~s})$. The element type Grunt was recorded in about $3 \%$ of the sequences. The duration of the variant GR1 varied significantly 
between sequence $6(0.11 \pm 0.3 \mathrm{~s})$, sequence $7(0.14 \pm 0.1 \mathrm{~s})$, and sequence $9(0.14 \pm 0.1 \mathrm{~s})$ (Kruskal-Wallis test, $p=0.005$ ); the variant GR2 presented a harmonic-like structure likely due to high click's repetition rate. The acoustic structure of Squeak (3\%), Crack (4\%), Pop $(10 \%)$, and $\mathrm{LFN}(<1 \%)$ was similar to the ones reported by [18].
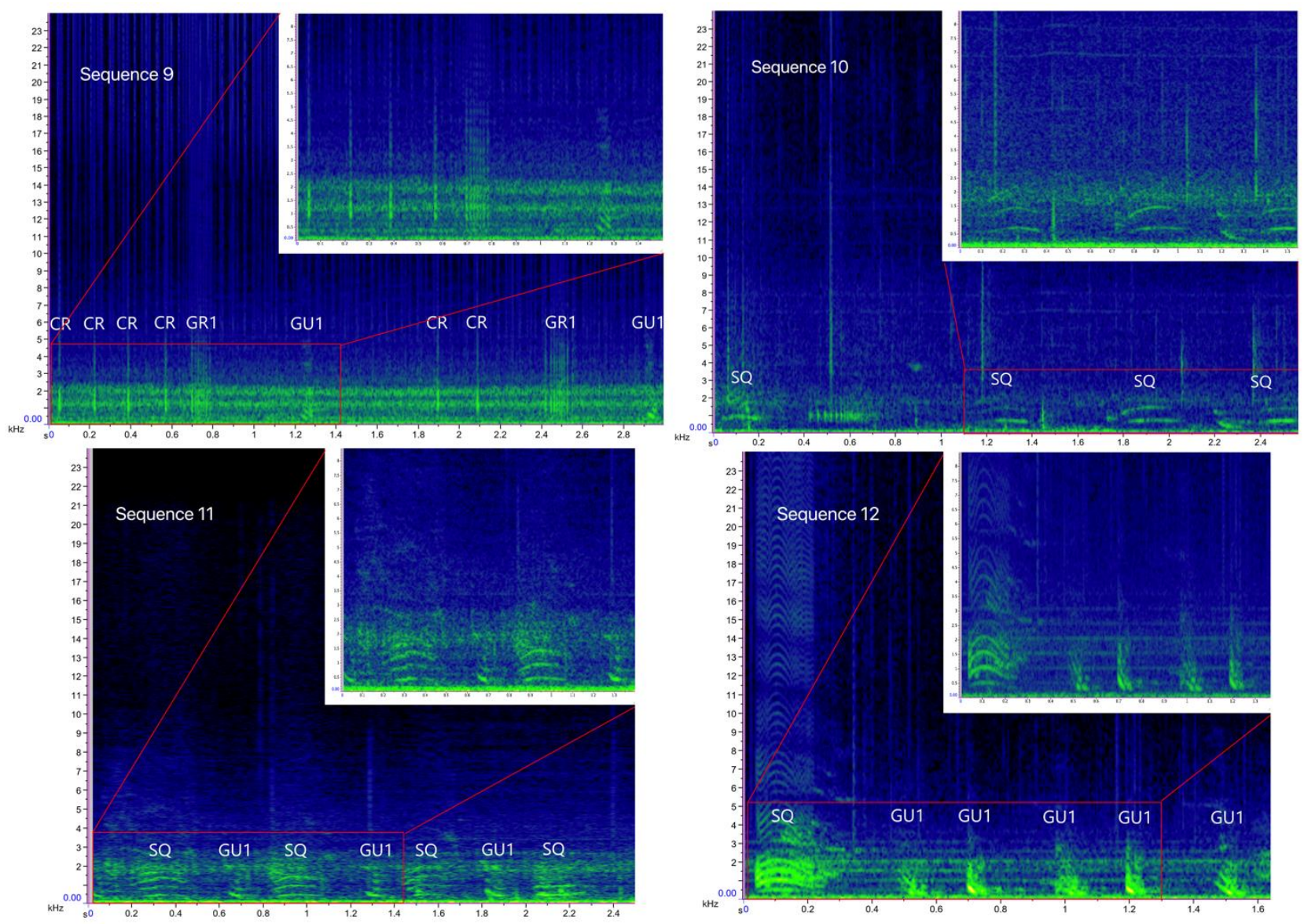

$\mathrm{kHz} 2000$
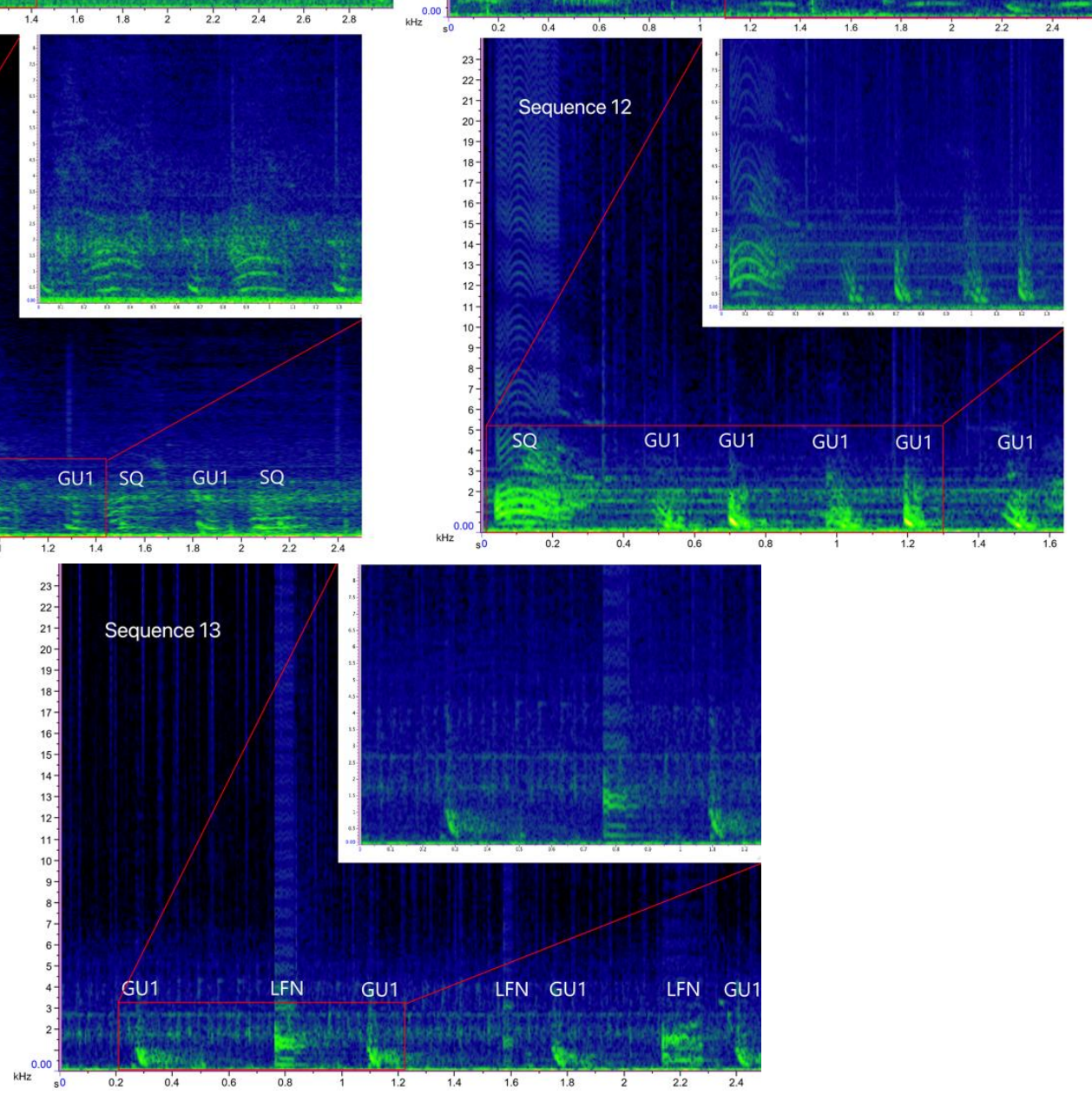

Figure 5. Spectrograms of the bray-call sequences 9-13 identified in the present study (main panels: Hann window, size 2048, DFT 2048, overlap 50\%, hop size 1024, sampling frequency $192 \mathrm{kHz}$, frequency resolution $93.75 \mathrm{~Hz}$, analysis bandwidth $135 \mathrm{~Hz}$ at $-3 \mathrm{~dB}$ ); zoomed panels: Hann window, size 3000, DFT 4096, overlap 80\%, hop size 600, sampling frequency $192 \mathrm{kHz}$, frequency resolution $46.875 \mathrm{~Hz}$, analysis bandwidth $92.16 \mathrm{~Hz}$ at $-3 \mathrm{~dB}$ ). 


\begin{tabular}{|c|c|c|c|c|c|c|c|c|c|c|c|c|c|c|c|c|}
\hline Sequence 1 & GU1 & GU1 & GU1 & GU1 & GU1 & GU1 & GU1 & GU1 & GU1 & & & & & & & \\
\hline Sequence 2 & GU3 & GU1 & & GU3 & IU1 & GU: & GU & & GU3 & GU1 & & & & & & \\
\hline Sequence 3 & GU1 & GU4 & & GU1 & UU4 & GU & $\mathrm{GU}$ & & GU1 & GU4 & & & & & & \\
\hline Sequence 4 & GU1 & GU2 & GU: & & U1 & GU2 & GU3 & GU1 & GU & GL & & & & & & \\
\hline Sequence 5 & POP & POP & POP & $\mathrm{POP}$ & $\mathrm{POP}$ & POP & POP & POP & POP & GU1 & & & & & & \\
\hline Sequence 6 & GR1 & GU1 & GU1 & GU1 & GU1 & GU1 & GU1 & GR1 & GU1 & GU1 & GU1 & GU1 & GU1 & GU1 & & \\
\hline Sequence 7 & GR1 & GU1 & GR1 & GU1 & GR1 & GU1 & GR1 & GU1 & GR1 & GU1 & GR1 & GU1 & & & & \\
\hline Sequence 8 & GR2 & GU1 & GR2 & GU1 & GR2 & GU1 & GR2 & GU1 & GR2 & GU1 & GR2 & GUl & & & & \\
\hline Sequence 9 & $\mathrm{CR}$ & $\mathrm{CR}$ & $\mathrm{CR}$ & CR & $\mathrm{CR}$ & $\mathrm{CR}$ & GR1 & GU1 & $\mathrm{CR}$ & $\mathrm{CR}$ & $\mathrm{CR}$ & $\mathrm{CR}$ & $\mathrm{CR}$ & $\mathrm{CR}$ & GR1 & GU1 \\
\hline Sequence 10 & SQ & SQ & SQ & SQ & SQ & SQ & SQ & SQ & SQ & SQ & SQ & SQ & & & & \\
\hline Sequence 11 & SQ & GU1 & SQ & GU1 & SQ & GU1 & SQ & GU1 & SQ & GU1 & SQ & GU1 & & & & \\
\hline Sequence 12 & SQ & GU1 & GU1 & GU1 & GU1 & GU1 & GU1 & SQ & GU1 & GU1 & GU1 & GU1 & GU1 & GU1 & & \\
\hline Sequence 13 & LFN & GU1 & LFN & GU1 & LFN & GU1 & LFN & GU1 & LFN & GU1 & LFN & GU1 & & & & \\
\hline
\end{tabular}

Figure 6. Bray-call sequences identified in this study met five distinct paradigms suggested by [1] for information encoding (repetition, diversity, combination, ordering, and timing).

The first-order Markov chain model (FOMM) showed that the transition probability between the acoustic element composing the bray-call sequences is not uniform. The highest probability is for a Gulp to be followed by another Gulp $\left(P_{\mathrm{GU}-\mathrm{GU}}=0.95\right)$, then the probability that a Gulp is followed by a Grunt $\left(\mathrm{P}_{\mathrm{GU}-\mathrm{GR}}=0.83\right)$ and the probability that a Gulp is followed by a Squeak $\left(\mathrm{P}_{\mathrm{GU}-\mathrm{SQ}}=0.43\right)$; single-element sequences of repeated Squeak showed a probability of occurrence of approximately $60 \%\left(\mathrm{P}_{\mathrm{SQ}-\mathrm{SQ}}=0.57\right)$ (Figure 7 , left side). The FOMM also revealed that there is a very high probability to observe GU1 followed by GU3 ( $\mathrm{P}_{\mathrm{GU} 1-\mathrm{GU} 3}=0.97$ ) and vice-versa $\left(\mathrm{P}_{\mathrm{GU}}\right.$-GU1 $\left.=0.92\right)$, GU3 followed by GU2 ( $\left.\mathrm{P}_{\mathrm{GU} 3-\mathrm{GU} 2}=0.96\right)$ and GU4 followed by GU1 ( $\left.\mathrm{P}_{\mathrm{GU} 4-\mathrm{GU} 1}=0.88\right)$. The GU2, GU3, and GU4 variants have never been observed in sequences with Squeaks or Grunts (Figure 7, right side).
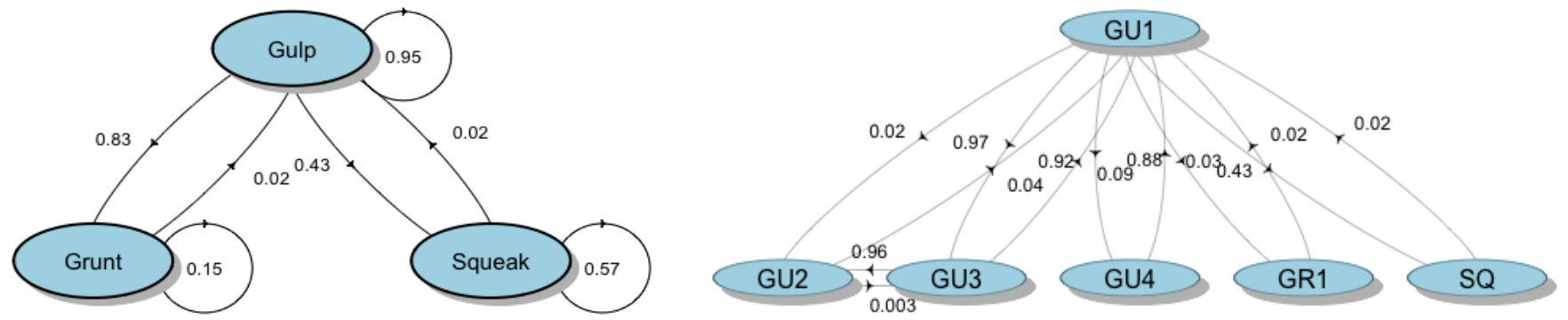

Figure 7. Transition diagrams of bray-call series obtained from first-order Markov chain model. The circles represent different vocal elements, and the values represent the transition probabilities.

Average values of the acoustic parameters of the 13 sequences, and of the element types and variants measured in each sequence, are reported in Table 4. Minimum frequency (Welch $t$-test: $t=-9.4845, \mathrm{df}=48.703, p<0.001$ ), maximum frequency (Mann-Whitney: $\mathrm{W}=219, p<0.001$ ) and element duration (Mann-Whitney: $\mathrm{W}=288, p<0.05$ ) of Sequence 1 (the most recorded sequence) resulted to vary significantly between study areas, with lower values measured in the Strait of Sicily (Figure 8). No significant difference resulted for period and sequence duration. 
Table 4. Average values of the acoustic parameters of the 13 bray-call sequences, and of the element types and variants measured in each sequence.

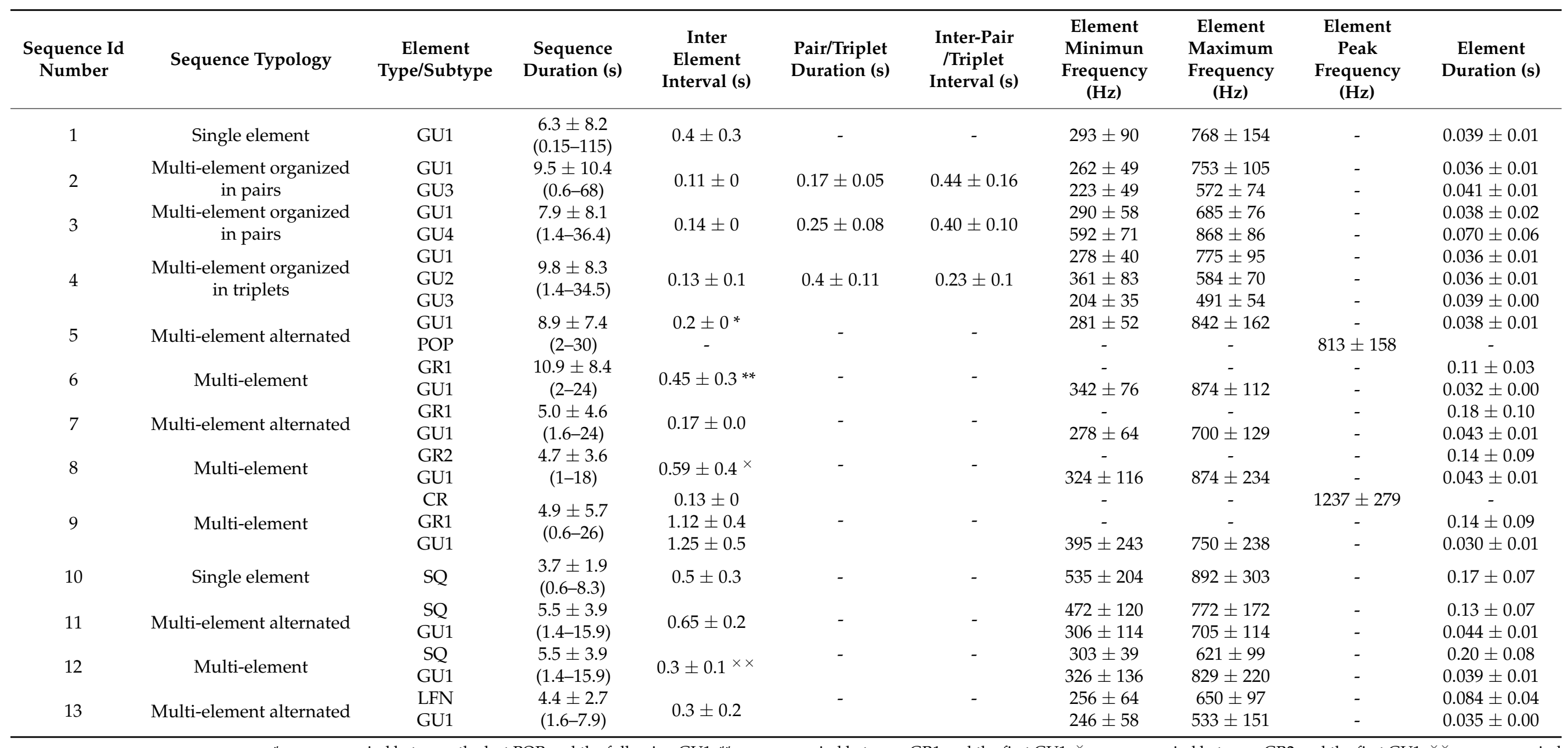

* average period between the last POP and the following GU1; ** average period between GR1 and the first GU1; ${ }^{\times}$average period between GR2 and the first GU1; $\times \times$average period between SQ and the first GU. 


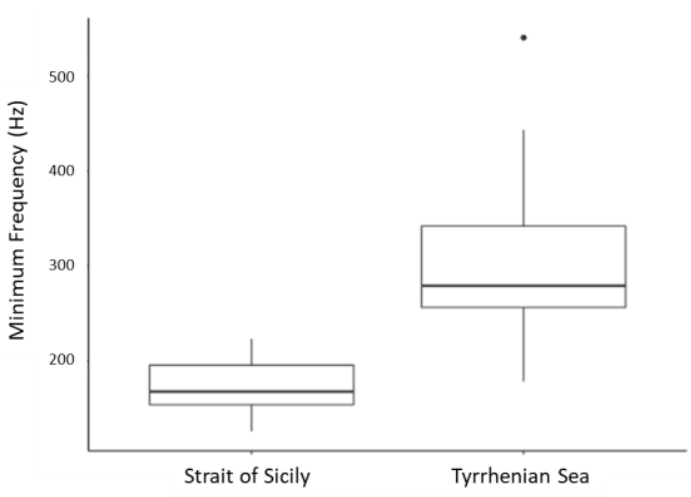

(a)

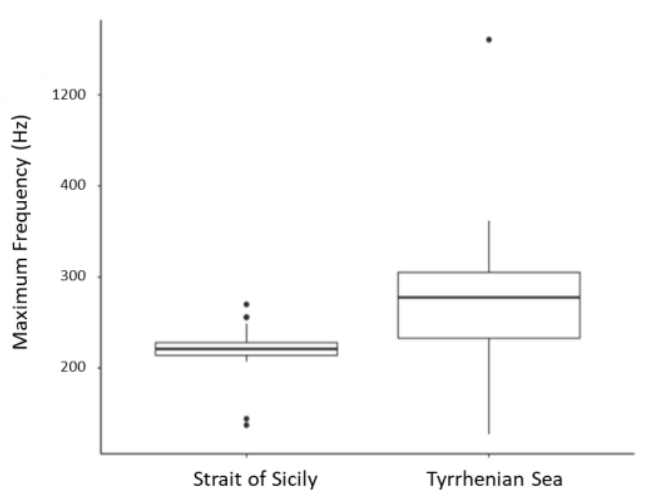

(b)

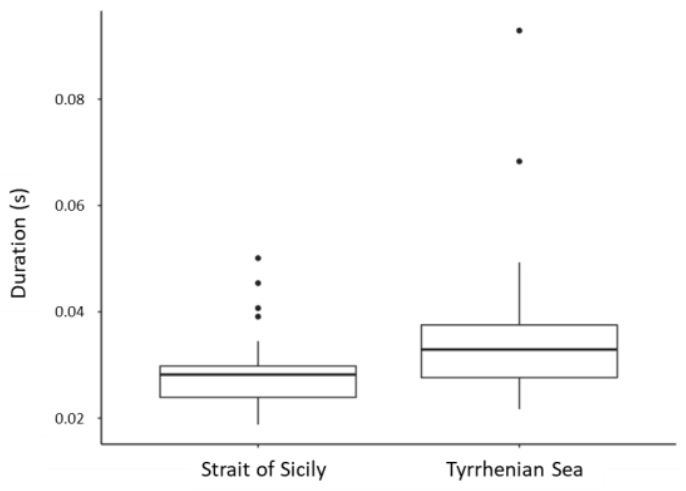

(c)

Figure 8. Box plots showing the distribution of minimum frequency $(\mathrm{Hz})(\mathbf{a})$, maximum frequency $(\mathrm{Hz})(\mathbf{b})$, and duration (s) (c) of Sequence 1 in the two study areas.

\section{Discussion}

Acoustic sequences are common events in many animal taxa [1] and their adaptive role has been intensively studied [41]. In common bottlenose dolphin, the structure, characteristics, and use of bray-call series have been investigated in few geographical areas (Portugal: [17,19,20,42]; Scotland: [24,25]; Gulf of Mexico: [43]; Namibia: [22]) and this is the first study that aimed to provide a detailed acoustic description of bray-call sequences from two different sites of the Mediterranean Sea. Here, three main elements composing the sequences have been identified (Gulp, Grunt, and Squeak), as in other studies [17,24,43]. However, the detailed acoustic analysis of the elements led to the description of 4 Gulp variants, identified for the first time in the present study, 2 Grunt variants and the presence of non-bray elements (POP, Crack, and LFN) within the sequences.

The GU1 variant was the most frequent and has been found in all multi-element sequences, suggesting a possible central role in the bray-call series in both Mediterranean sites. The visual classification and the acoustic features of GU1, GU2, and GU4 variants here described do not match with previous Gulp descriptions found in the literature, whereas the variant GU3 shows a high level of similarity with the Gulp described by [17] when considering minimum frequency, maximum frequency, and duration. The variant GR1 seems like the Grunt described by [17], while the variant GR2 shows similarities with one Grunt category recorded in the Guiana dolphin (Sotalia guianensis) [44]. The element SQ appears to have similar acoustic characteristics with the Squeak described by [17] in common bottlenose dolphins off Portugal's coast. LFN sounds here identified are comparable to [18] but different from [43] as they show higher values of minimum frequency, maximum frequency and duration, even though they share an analogous harmonic structure, and are emitted in series. Finally, in this study CRs are as described by [18] and POPs are similar to [38], who reported that these sounds are emitted in series of 3-30 during agonistic interactions between males. 
Overall, these results seem to suggest that Mediterranean common bottlenose dolphin sub-populations may compose sequence using several different acoustic elements and arrange them in a very flexible and complex way to produce distinct sequence types. Indeed, 13 different sequences have been identified, with a different transition probability among elements composing them (as observed by [17]). Two of them are composed by the repetition of a single acoustic element (GU1 in sequence 1 and SQ in sequence 10). The repetition of the same acoustic element within a sequence is reported as a transversal rule for encoding information in mammals' communication $[45,46]$ and the number of elements per sequence may influence the information codified in the message [1]. Repetition may be used to confirm [47], substitute or reinforce the message [48]. Indeed, a high repetition rate of the same acoustic signal has been often observed in contexts where the correct transmission of the message is fundamental for survival, as in dangerous (e.g., suricates, Suricata suricata [49]; marmots, Marmota spp. [8]; colobuses, Colobus spp. [50]; Campbell's monkey, Cercopithecus campbelli campbelli [51]; lemurs, Lemur catta and Varecia variegate [52]) or foraging situations (e.g., big-footed myotis, Myotis macrodactylus [53]) in terrestrial mammals, and in noisy environments (e.g., blue whale, Balaenoptera musculus [54]; killer whale, Orcinus orca [55]) in marine mammals. The multi-element sequences identified in the study include seven typologies characterized by a higher level of diversity, timing, and combination of acoustic elements (Sequences 5, 6, 7, 8, 11, 12, and 13) and four typologies characterized by a specific repetition order of pairs and triads (Sequences 2, 3, 4, and 9). Complex acoustic sequences are parts of the vocal repertoire of many animal species and are used for different purposes: improving the communication efficiency (e.g., colonies of bats, Pipistrellus pipistrellus [56]), simplifying individual recognition (e.g., humpback whale, Megaptera novaeangliae [13]), rejecting competitors and predators (e.g., Campbell's monkey, Cercopithecus campbelli [57]) and during courtship behavior (e.g., common grackles, Quiscalus quiscula [58]). It remains to be investigated if bray-call sequences may play similar roles in common bottlenose dolphin communication. Here, five distinct paradigms for encoding information in sequences (Repetition, Diversity, Combination, Ordering and Timing; [1]) are met, but not overlapping between sequences (likely individuals were not vocalizing at the same time in the analyzed dataset). It was not possible to understand with certainty whether each sequence was only emitted by one animal or whether the sequence was made with the contribution of other animals. Thus, the hypotheses of a sequence emitted by one specimen or a coordination among several individuals persist until more body of evidence comes along. In addition, it is important to note that "sequences of sequences" have not been examined in the present study, thus more complex levels of combinations are yet to be explored. In the Tyrrhenian Sea, bray call series showed a rate of 0.09 per minute, a value three-folds higher than the Strait of Sicily. The two study sites share two single element sequences (Sequence 1 and 10, possibly part of a more general repertoire shared at least among Mediterranean and Eastern Atlantic [59]), while multi-element sequences have been identified in the Tyrrhenian Sea only. The SDC index confirmed the high degree of dissimilarity between the bray-call repertoire of the two sub-populations. In cetacean species, it is known that local, ecological, and social specificities, such as group size, composition, and ecology may affect distribution and acoustic variations within populations (e.g., [60,61]). Here, bray-call differences in common bottlenose dolphins in the Tyrrhenian Sea and in the Strait of Sicily may have been shaped by such factors. In the Tyrrhenian Sea, several individuals show a high level of site fidelity [26]. Such a strong residency pattern seems not present in the Strait of Sicily, where a core of female shows site fidelity - even if lower than the Tyrrhenian sub-population-but a great number of individuals likely temporarily transient in the area $[30,62]$. Thus, the use of a more complex code of communication like bray-call sequences might be not useful to share information among individuals in this sub-population. In the Tyrrhenian Sea, photoidentification analysis revealed that resident dolphins (mostly females) have been observed in more than $65 \%$ of encounters with bray-call detection. Although common bottlenose dolphins are characterized by a fission-fusion social structure [63], they can establish long-term social 
relationships when inhabiting a specific area permanently. This phenomenon has been observed especially for females residing in estuary regions that coexist durably $[64,65]$ (as in the Tyrrhenian Sea) and may explain the development of local communicative acoustic signals used to improve the group cohesion and facilitate individuals' coordination. The presence of bray-call during social interactions [19] in an estuary area, and in feeding situations $[24,25]$, seems to support their possible communicative role in both contexts. More specifically, $[24,66]$ supposed that bray-call sequences may be used by common bottlenose dolphins to manipulate specific prey's behavior and suggested that geographic differences in bray-call emissions may derive from a contextual learning process that is influenced by locally available prey. Unravelling the role of sequences might support discriminating different activity contexts, providing a new tool for studying habitat use and behavior through acoustic cues.

In this study, the acoustic parameters extracted from sequences and acoustic elements revealed variations between the two geographical areas when considering low frequency, high frequency, and element durations. Geographical variability in frequency and duration has been largely documented for other common bottlenose dolphin call types, such as whistles $[60,67,68]$, and may has been developed as local adaptations to environmental variability $[60,62,67-70]$. Thus, studying the occurrence of these sequences could help in identifying different sub-populations and local specializations. Acoustic characterization of different populations and information sharing [71,72] have been proven to be useful for conservation, and this could be highly relevant for the common bottlenose dolphin in the Mediterranean Sea, a species listed in the Annex II of EU Habitats Directive (92/43/CEE).

\section{Conclusions}

In conclusion, this study proposed for the first time, quantification, depiction, and detailed description of common bottlenose dolphin bray-call sequences in the Mediterranean Sea, providing new and complete information about these vocalizations. Further research is needed to better understand their function(s) in feeding and social contexts (even extreme ones, like when a dead individual is present [73]), considering both their structural complexity and emission circumstances. In addition, due to the distinctiveness of the sequence structures, disruptions caused by anthropogenic (e.g., noise, fishery) and biological factors (e.g., prey type), as well as social and behavioral conditions, could be clearly revealed from the analysis of their patterns.

Author Contributions: Conceptualization: D.S.P., G.G., and G.A.; field work: D.S.P., C.T., G.G., M.S., G.P. (Giulia Pedrazzi), E.P., M.C., and G.B.; acoustic analysis: C.T., M.S., G.P. (Giulia Pedrazzi), G.P. (Gianni Pavan), and D.S.P.; statistical analysis: C.T., M.S., G.P. (Giulia Pedrazzi), and D.S.P.; writing: D.S.P., C.T., G.G., G.P. (Giulia Pedrazzi), M.S.; revision and approval: All authors. All authors have read and agreed to the published version of the manuscript.

Funding: In the Tyrrhenian Sea, in 2017-2018, this work was supported by OceanCare (Switzerland) and in 2019-2020 by Cooperativa Pelagos (Italy). In 2020, this work was partially funded by Lazio Region (Italy) within PO FEAMP 2014/2020-Misura 1.40 framework, "DelPHEos" project.

Institutional Review Board Statement: Not applicable.

Informed Consent Statement: Not applicable.

Data Availability Statement: The data presented in this study are available to any qualified researcher on request from the corresponding author.

Acknowledgments: We would like to thank the Secche di Tor Paterno (MPA) and Roma Natura for the logistic support; I Barcaroli del Dollaro and the local professional/recreational fishing community for their help; Chiara di Marco, Sara Marini, Sara Ferri, and Alessandro Frachea for their assistance in the 2019 field season; Sara Verni for her assistance in the 2020 field season; Maria Cristina Gambi, Raffaella Tizzi, Caterina Lanfredi, Junio Fabrizio Borsani, Sabina Airoldi, Antonella Arcangeli, Giovanna JonaLasinio and Francesca Triossi for the constant encouragement; and Chiara Giulia Bertulli for the English advice. 
Conflicts of Interest: The authors declare no conflict of interest.

\section{References}

1. Kershenbaum, A.; Blumstein, D.T.; Roch, M.A.; Akçay, Ç.; Backus, G.; Bee, M.A.; Bohn, K.; Cao, Y.; Carter, G.; Caesar, C.; et al. Acoustic sequences in non-human animals: A tutorial review and prospectus. Biol. Rev. 2016, 91, 13-52. [CrossRef]

2. Gerhardt, H.C.; Huber, F. Acoustic Communication in Insects and Anurans: Common Problems and Diverse Solutions; Chicago University Press: Chicago, IL, USA, 2002.

3. Gentner, T.Q.; Hulse, S.H. Perceptual mechanisms for individual vocal recognition in European starlings, Sturnus vulgaris. Anim. Behav. 1998, 56, 579-594. [CrossRef]

4. Root-Gutteridge, H.; Bencsik, M.; Chebli, M.; Gentle, L.K.; Terrell-Nield, C.; Bourit, A.; Yarnell, R.W. Identifying individual wild Eastern grey wolves (Canis lupus lycaon) using fundamental frequency and amplitude of howls. Bioacoustics 2014, $23,55-66$. [CrossRef]

5. Sayigh, L.S.; Esch, H.C.; Wells, R.S.; Janik, V.M. Facts about signature whistles of bottlenose dolphins, Tursiops truncatus. Anim. Behav. 2007, 74, 1631-1642. [CrossRef]

6. Courts, R.; Erbe, C.; Wellard, R.; Boisseau, O.; Jenner, K.C.; Jenner, M.N. Australian long-finned pilot whales (Globicephala melas) emit stereotypical, variable, biphonic, multi-component, and sequenced vocalisations, similar to those recorded in the northern hemisphere. Sci. Rep. 2020, 10, 20609. [CrossRef] [PubMed]

7. Slocombe, K.E.; Zuberbuhler, K. Food-associated calls in chimpanzees: Responses to food types or food preferences? Anim. Behav. 2006, 72, 989-999. [CrossRef]

8. Blumstein, D.T. The evolution, function, and meaning of marmot alarm communication. Adv. Study Behav. 2007, 37, 371-401.

9. Schel, A.M.; Tranquilli, S.; Zuberbühler, K. The alarm call system of two species of black-and-white colobus monkeys (Colobus polykomos and Colobus guereza). J. Comp. Psychol. 2009, 123, 136-150. [CrossRef]

10. Gero, S.; Whitehead, H.; Rendell, L. Individual, unit and vocal clan level identity cues in sperm whale codas. R. Soc. Open Sci. 2016, 3, 150372. [CrossRef] [PubMed]

11. Pace, D.S.; Lanfredi, C.; Airoldi, S.; Giacomini, G.; Silvestri, M.; Pavan, G.; Ardizzone, D. Trumpet sounds emitted by male sperm whales in the Mediterranean Sea. Sci. Rep. 2021, 11, 5867. [CrossRef]

12. Ford, J.K. Vocal traditions among resident killer whales (Orcinus orca) in coastal waters of British Columbia. Can. J. Zool. 1991, 69, 1454-1483. [CrossRef]

13. Payne, R.S.; Mcvay, S. Songs of humpback whales. Science 1971, 173, 585-597. [CrossRef] [PubMed]

14. Zwamborn, E.M.J.; Whitehead, H. Repeated call sequences and behavioural context in long-finned pilot whales off Cape Breton, Nova Scotia, Canada. Bioacoustics 2017, 26, 169-183. [CrossRef]

15. Caldwell, M.C.; Caldwell, D.K. Individualized whistle contours in bottlenose dolphins (Tursiops truncatus). Nature 1965, 207, 434-435. [CrossRef]

16. Janik, V.M.; King, S.L.; Sayigh, L.S.; Wells, R.S. Identifying signature whistles from recordings of groups of unrestrained bottlenose dolphins (Tursiops truncatus). Mar. Mamm. Sci. 2013, 29, 109-122. [CrossRef]

17. Luís, A.R.; Alves, I.S.; Sobreira, F.V.; Couchinho, M.N.; dos Santos, M.E. Brays and bits: Information theory applied to acoustic communication sequences of bottlenose dolphins. Bioacoustics 2019, 28, 286-296. [CrossRef]

18. Jones, B.; Zapetis, M.; Samuelson, M.M.; Ridgway, S. Sounds produced by bottlenose dolphins (Tursiops truncatus): A review of the defining characteristics and acoustic criteria of the dolphin vocal repertoire. Bioacoustics 2019, 29, 399-440. [CrossRef]

19. Dos Santos, M.E.; Caporin, G.; Moreira, H.O.; Ferreira, A.J.; Coelho, J.L.B. Acoustic behavior in a local population of bottlenose dolphins. In Sensory Abilities of Cetaceans; Thomas, J.A., Kastelein, R.A., Eds.; Springer: Boston, MA, USA, 1990; pp. 585-598.

20. Dos Santos, M.E.; Ferreira, A.J.; Harzen, S. Rhythmic sound sequences emitted by aroused bottlenose dolphins in the Sado Estuary, Portugal. In Sensory Systems of Aquatic Mammals; Evans, P.G.H., Nice, H., Eds.; De Spil Publishers: Woerden, The Netherlands, 1995; pp. 325-334.

21. López, B.; Shirai, J. Mediterranean common bottlenose dolphin's repertoire and communication use. In Dolphins: Anatomy, Behavior, and Threats; Pierce, L., Correa, A.G., Eds.; Nova Science Publishers: New York, NY, USA, 2009; pp. $129-148$.

22. Gridley, T.; Nastasi, A.; Kriesell, H.J.; Elwen, S.H. The acoustic repertoire of wild common bottlenose dolphins (Tursiops truncatus) in Walvis Bay, Namibia. Bioacoustics 2015, 24, 153-174. [CrossRef]

23. Herzing, D.L. Synchronous and rhythmic vocalizations and correlated underwater behavior of free-ranging atlantic spotted dolphins (Stenella frontalis) and bottlenose dolphins (Tursiops truncatus) in the Bahamas. Anim. Behav. Cogn. 2015, 2, 14-29. [CrossRef]

24. Janik, V.M. Food-related bray calls in wild bottlenose dolphins (Tursiops truncatus). Proc. R. Soc. B 2000, 267, 923-927. [CrossRef] [PubMed]

25. King, S.L.; Janik, V.M. Come dine with me: Food-associated social signalling in wild bottlenose dolphins (Tursiops truncatus). Anim Cogn. 2015, 18, 969-974. [CrossRef] [PubMed]

26. Pace, D.S.; Di Marco, C.; Giacomini, G.; Ferri, S.; Silvestri, M.; Papale, E.; Casoli, E.; Ventura, D.; Mingione, M.; Alaimo Di Loro, P.; et al. Capitoline dolphins: Residency patterns and abundance estimate of Tursiops truncatus at the Tiber River estuary (Mediterranean Sea). Biology 2021, 10, 275. [CrossRef] 
27. Pace, D.S.; Giacomini, G.; Campana, I.; Paraboschi, M.; Pellegrino, G.; Silvestri, M.; Alessi, J.; Angeletti, D.; Cafaro, V.; Pavan, G.; et al. An integrated approach for cetacean knowledge and conservation in the central Mediterranean Sea using research and social media data sources. Aquat. Conserv. Mar. Freshw. Ecosyst. 2019, 29, 1302-1323. [CrossRef]

28. Triossi, F.; Willis, T.J.; Pace, D.S. Occurrence of bottlenose dolphins Tursiops truncatus in natural gas fields of the northwestern Adriatic S ea. Mar. Ecol. 2013, 34, 373-379. [CrossRef]

29. Martino, S.; Pace, D.S.; Moro, S.; Casoli, E.; Ventura, D.; Frachea, A.; Silvestri, M.; Arcangeli, A.; Giacomini, G.; Ardizzone, G.D.; et al. Integration of presence-only data from several data sources. A case study on dolphins' spatial distribution. Ecography 2021, 44, 1533-1543. [CrossRef]

30. Papale, E.; Ceraulo, M.; Giardino, G.; Buffa, G.; Filiciotto, F.; Grammauta, R.; Maccarone, V.; Mazzola, S.; Buscaino, G. Association patterns and population dynamics of bottlenose dolphins in the Strait of Sicily (Central Mediterranean Sea) implication for management. Soc. Popul. Ecol. 2016, 59, 55-64. [CrossRef]

31. Papale, E.; Alonge, G.; Grammauta, R.; Ceraulo, M.; Giacoma, C.; Mazzola, S.; Buscaino, G. Year-round acoustic patterns of dolphins and interaction with anthropogenic activities in the Sicily Strait, central Mediterranean Sea. Ocean Coast. Manag. 2020, 197, 105320. [CrossRef]

32. Parra, G.J. Resource partitioning in sympatric delphinids: Space use and habitat preferences of Australian snubfin and Indo-Pacific humpback dolphins. J. Anim. Ecol. 2006, 75, 862-874. [CrossRef] [PubMed]

33. Mann, J. Behavioral sampling methods for cetaceans: A review and critique. Mar. Mamm. Sci. 1999, 15, 102-122. [CrossRef]

34. Mariani, M.; Miragliuolo, A.; Mussi, B.; Russo, G.F.; Ardizzone, G.; Pace, D.S. Analysis of the natural markings of Risso's dolphins (Grampus griseus) in the central Mediterranean Sea. J. Mammal. 2016, 97, 1512-1524. [CrossRef]

35. Corkeron, P.J.; Minton, G.; Collins, T.; Findlay, K.; Willson, A.; Baldwin, R. Spatial models of sparse data to inform cetacean conservation planning: An example from Oman. Endang. Species Res. 2011, 15, 39-52. [CrossRef]

36. Papale, E.; Alonge, G.; Caruso, F.; Grammauta, R.; Mazzola, S.; Mussi, B.; Pace, D.S.; Buscaino, G. The higher, the closer, the better? Influence of sampling frequency and distance on the acoustic properties of short-beaked common dolphins burst pulses in the Mediterranean Sea. Aquat. Conserv. Mar. Freshw. Ecosyst. 2021, 31, 51-60. [CrossRef]

37. Center for Conservation Bioacoustics. Raven Pro: Interactive Sound Analysis Software, Version 2.0; Cornell Laboratory of Ornithology: Ithaca, NY, USA, 2019; Available online: https:/ / ravensoundsoftware.com/ (accessed on 18 December 2021).

38. Connor, R.C.; Smolker, R.A. Pop' goes the dolphin: A vocalization male bottlenose dolphin produced during courtships. Behaviour 1996, 133, 643-662.

39. Gottman, J.M.; Roy, A.K. Sequential Analysis; Cambridge University Press: Cambridge, UK, 1990.

40. Shannon, C.E. 1948. A mathematical theory of communication. Bell. Syst. Tech. J. 1948, 27, 379-423. [CrossRef]

41. Fedurek, P.; Zuberbühler, K.; Semple, S. Trade-offs in the production of animal vocal sequences: Insights from the structure of wild chimpanzee pant hoots. Front. Zool. 2017, 14, 50. [CrossRef] [PubMed]

42. Luís, A.R.; Couchinho, M.N.; dos Santos, M.E. A quantitative analysis of pulsed signals emitted by wild bottlenose dolphins. PLoS ONE 2016, 11, e0157781. [CrossRef] [PubMed]

43. Simard, P.; Lace, N.; Gowans, S.; Quintana-Rizzo, E.; Kuczaj, A.S.; Wells, S.R.; Mann, A.D. Low frequency narrow-band calls in bottlenose dolphins (Tursiops truncatus): Signal properties, function, and conservation implications. J. Acoust. Soc. Am. 2011, 130, 3068-3076. [CrossRef]

44. Barbosa, M.; Bittencourt, L.; Bisi, T.L.; Lailson-Brito, J.; Azevedo, A.F. Characterisation and classification method of burst pulses produced by Guiana dolphins (Sotalia guianensis). Bioacoustics 2022, 31, 69-80. [CrossRef]

45. Fischer, J.; Hammerschmidt, K. Functional referents and acoustic similarity revisited: The case of Barbary macaque alarm calls. Anim Cogn. 2001, 4, 29-35. [CrossRef]

46. Schehka, S.; Esser, K.H.; Zimmermann, E. Acoustical expression of arousal in conflict situations in tree shrews (Tupaia belangeri). J. Comp. Physiol. A 2007, 193, 845-852. [CrossRef]

47. Wiley, R.H. Errors, exaggeration, and deception in animal communication. In Behavioral Mechanisms in Evolutionary Ecology; Real, L., Ed.; University of Chicago Press: Chicago, IL, USA, 1994; pp. 157-189.

48. Payne, R.J.H.; Pagel, M. Why do animals repeat displays? Anim. Behav. 1997, 54, 109-119. [CrossRef] [PubMed]

49. Manser, M.B. The acoustic structure of suricates' alarm calls varies with predator type and the level of response urgency. Proc. R. Soc. B 2001, 268, 2315-2324. [CrossRef] [PubMed]

50. Schel, A.M.; Candiotti, A.; Zuberbühler, K. Predator-deterring alarm call sequences in Guereza colobus monkeys are meaningful to conspecifics. Anim. Behav. 2010, 80, 799-808. [CrossRef]

51. Lemasson, A.; Ouattara, K.; Bouchet, H.; Zuberbühler, K. Speed of call delivery is related to context and caller identity in Campbell's monkey males. Sci. Nat. 2010, 97, 1023-1027. [CrossRef] [PubMed]

52. Macedonia, J.M. What is communicated in the antipredator calls of lemurs: Evidence from playback experiments with ring tailed and ruffed lemurs. Ethology 1990, 86, 177-190. [CrossRef]

53. Guo, D.; Ding, J.; Liu, H.; Zhou, L.; Feng, J.; Luo, B.; Liu, Y. Social calls influence the foraging behavior in wild big-footed myotis. Front. Zool. 2021, 18, 3. [CrossRef] [PubMed]

54. Miller, P.J.O.; Biassoni, N.; Samuels, A.; Tyack, P.L. Whale songs lengthen in response to sonar. Nature 2000, 405, 903. [CrossRef] [PubMed]

55. Foote, A.D.; Osborne, R.W.; Hoelzel, A.R. Whale-call response to masking boat noise. Nature 2004, 428, 910. [CrossRef] [PubMed] 
56. Budenz, T.; Heib, S.; Kusch, J. Functions of bat social calls: The influence of local abundance, interspecific interactions and season on the production of pipistrelle (Pipistrellus pipistrellus) type D social calls. Acta Chiropt. 2009, 11, 173-182. [CrossRef]

57. Ouattara, K.; Lemasson, A.; Zuberbühler, K. Campbell's monkeys concatenate vocalizations into context-specific call sequences. Proc. Natl. Acad. Sci. USA 2009, 106, 22026-22031. [CrossRef] [PubMed]

58. Searcy, W.A. Song repertoire and mate choice in birds. Am. Zool. 1992, 32, 71-80. [CrossRef]

59. Luís, A.R.; May-Collado, L.J.; Rako-Gospić, N.; Gridley, T.; Papale, E.; Azevedo, A.; Silva, M.A.; Buscaino, G.; Herzing, D.; dos Santos, M.E. Vocal universals and geographic variations in the acoustic repertoire of the common bottlenose dolphin. Sci. Rep. 2021, 11, 11847. [CrossRef]

60. Pace, D.S.; Arcangeli, A.; Mussi, B.; Vivaldi, C.; Ledon, C.; Lagorio, S.; Giacomini, G.; Pavan, G.; Ardizzone, G. Habitat suitability modeling in different sperm whale social groups. J. Wildl. Manag. 2018, 82, 1062-1073. [CrossRef]

61. Azzolin, M.; Gannier, A.; Papale, E.; Papale, B.G.; Mussi, B.; Ardizzone, G.; Giacoma, C.; Pace, D.S. Whistle variability of the Mediterranean short beak common dolphin. Aquat. Conserv. Mar. Freshw. Ecosyst. 2021, 31, 36-50. [CrossRef]

62. Gregorietti, M.; Papale, E.; Ceraulo, M.; de Vita, C.; Pace, D.S.; Tranchida, G.; Mazzola, S.; Buscaino, G. Acoustic Presence of Dolphins through Whistles Detection in Mediterranean Shallow Waters. J. Mar. Sci. Eng. 2021, 9, 78. [CrossRef]

63. Connor, R.C.; Wells, R.S.; Mann, J.; Read, A.J. The bottlenose dolphin: Social relationships in a fission-fusion society. In Cetacean Societies: Field Studies of Dolphins and Whales; Mann, J., Connor, R.C., Tyack, P.L., Whitehead, H., Eds.; University of Chicago Press: Chicago, IL, USA, 2000; pp. 91-126.

64. Fury, C.A.; Harrison, P.L. Abundance, site fidelity and range patterns of Indo-Pacific bottlenose dolphins (Tursiops aduncus) in two Australian subtropical estuaries. Mar. Freshw. Res. 2008, 59, 1015-1027. [CrossRef]

65. Rossman, S.; Ostrom, P.H.; Stolen, M.; Barros, N.B.; Gandhi, H.; Stricker, C.A.; Wells, R.S. Individual specialization in the foraging habits of female bottlenose dolphins living in a trophically diverse and habitat rich estuary. Oecologia 2015, 178, 415-425. [CrossRef] [PubMed]

66. Janik, V.M.; Slater, P.J.B. The different roles of social learning in vocal communication. Anim. Behav. 2000, 60, 1-11. [CrossRef] [PubMed]

67. Hawkins, E.R. Geographic variations in the whistles of bottlenose dolphins (Tursiops truncatus) along the east and west coasts of Australia. J. Acoust. Soc. Am. 2010, 128, 924-935. [CrossRef]

68. La Manna, G.; Gospić, R.N.; Manghi, M.; Picciulin, M.; Sarà, G. Assessing geographical variation on whistle acoustic structure of three Mediterranean populations of common bottlenose dolphin (Tursiops truncatus). Behaviour 2017, 154, 583-607. [CrossRef]

69. Papale, E.; Gamba, M.; Perez-Gil, M.; Martin, V.M.; Giacoma, C. Dolphins adjust species-specific frequency parameters to compensate for increasing background noise. PLOS ONE 2015, 10, e0121711.

70. Wang, D.W.; Würsig, B.; Evans, W.E. Whistles of bottlenose dolphins: Comparisons among populations. Aquat. Mamm. 1995, 21, 65-77.

71. Méndez-Cárdenas, M.; Randrianambinina, B.; Rabesandratana, B.; Rasoloharijaona, S.; Zimmermann, E. Geographic variation in loud calls of sportive lemurs (Lepilemur ssp.) and their implications for conservation. Am. J. Primatol. 2008, 70, 828-838. [CrossRef]

72. Pace, D.S.; Mussi, B.; Gordon, J.C.; Wurtz, M. Foreword. Aquat. Conserv. Mar. Freshw. Ecosyst. 2014, 24, 1-3. [CrossRef]

73. Pedrazzi, G.; Giacomini, G.; Pace, D.S. First Report of Epimeletic and Acoustic Behavior in Mediterranean Common Bottlenose Dolphins (Tursiops truncatus) Carrying Dead Calves. Biology 2022, 11, 337. [CrossRef] 